\title{
Clinical presentation of pediatric SLE at outpatient clinic
}

\begin{abstract}
Background: Systemic lupus erythematosus (SLE) is a rheumatic disease resulting in damage to any organ in the body. $10-20 \%$ of SLE patients diagnosed in childhood.

Objective: To define the pattern of disease expression in pediatric SLE.

Sitting: Outpatient clinic of pediatric SLE of Abu Alrich hospital-Cairo-Egypt.

Subject: 25 pediatric SLE patients who attend the clinic.

Design of study: observational descriptive case series report.

Data collection: Data collected by second author during her residency in Abu Alrich hospital to study rheumatology. The 25 patients randomly selected. She collects medical history information directly from the patients and their parents and reviews their files to collect the other information (e.g.: investigation results and clinical examination and finding during course of the disease).

Results: From 25 patients Female to male ratio 2.3:1. Age at diagnosis range from 4 to 15 years with mean of 9 years. Duration of symptoms before diagnosis established range from one month to 7 years with mean of 8 months. Frequency of SLE classification criteria as follows: +ve ANA 95\%, renal disorder: $84 \%$, immunological disorder $60 \%$, photosensitivity $48 \%$, oral ulcers $48 \%$, Hematological disorder $44 \%$, arthritis $36 \%$, serositis $28 \%$, malar rash $12 \%$, discoid rash $4 \%$, neurological disorder $0 \%$. Other clinical manifestation of SLE include fever $80 \%$, arthralgia and anorexia $84 \%$ each, hair fall $40 \%$, abdominal pain $36 \%$, other skin manifestation $24 \%$, headache $20 \%$,dyspnea and palpitation $16 \%$ each, Reynard's phenomena and lymphadenopathy $12 \%$ each. The most frequent hematological abnormality: elevated ESR: 100\% anemia: 72\%, leucopenia: 44\%, thrombocytopenia: $20 \%$, leukocytosis: $12 \%$, thrombocytosis $8 \%$, lymphopenia: $4 \%$.

Conclusion and recommendation: The presentation and the clinical course of SLE have wide variability. Nephropathy, fever, anorexia and arthralgia were the most common presenting clinical manifestations in pediatric patients. There is marked delay between the starting of the disease manifestation and diagnosis, so alertness to the possibility of SLE as diagnosis in patients with variable manifestation should be there.
\end{abstract}

Keywords: Systemic lupus erythematosus, Rheumatic disease, Classification criteria
Volume 2 Issue I - 2015

\author{
Halima Mohamed Ben Amer \\ Pediatric department, Medical college of Benghazi university, \\ Libya \\ Correspondence: Halima Mohamed Ben Amer, Pediatric \\ department, Medical college of Benghazi university, Libya, \\ Email benamer_h@yahoo.co.uk
}

Received: October 25, 2014 | Published: January 2I, 2015

\section{Introduction}

Systemic lupus erythematosus (SLE) is a rheumatic disease characterized by autoantibody directed against self-antigens, immune complex formation, and immune deregulation, resulting in damage to essentially any organ. Childhood S L E generally presents between the ages of 4 and 15 years, with girls out numbering boys $4: 1 .{ }^{1}$ In 10-20\% of SLE patients the diagnosis is made for the first time in childhood. ${ }^{2-6}$ The disease can affect any organ but the most frequent are the kidneys, skin, blood vessels and cells, joints, heart and SLE nervous system The patients may present with many years of symptoms or with acute history of life-threatening disease ${ }^{7-9}$ Common initial and chronic complaints include fever, malaise, fatigue, joint pain, and temporary loss of cognitive abilities. Because they are so often seen with other diseases, these signs and symptoms are not part of the diagnostic criteria for SLE. When occurring in conjunction with other signs and symptoms they are considered suggestive. ${ }^{10}$ The American College of Rheumatology established eleven criteria as a classificatory instrument in $1982^{11}$ which were revised in $1997^{12}$ in clinical trials.

They were not intended to be used to diagnose individuals and do not do well in that capacity. For the purpose of identifying patients for clinical studies, a person has SLE if any 4 out of 11 symptoms are present simultaneously or serially on two separate occasions without other explanation. Classification criteria include: ${ }^{13} 1-$ malar rash. 2- discoid rash. 3- serositis. 4-oral ulcers. 5- photosensitivity.6arthritis .7-haematological changes (hemolytic anaemia, leucopenia, lymphopenia, thrombocytopenia) 8-Renal disorder. 9- +ve ANA. 10-Immunological disorder (eg: +ve double strand DNA, anti phospholipids anti body, anti smith). 11-CNS changes (eg: seizures, psycosis). The treatment of SLE involves preventing flares and reducing their severity and duration when they occur. It includes corticosteroids and anti-malarial drugs (hydroxychloroquin). Certain types of lupus nephritis such as diffuse proliferative glomerulonephritis require bouts of cytotoxic drugs. These drugs include azathioprin, mycophenolate, cyclophosphamide. Intra venous immunoglobulin also can be used in patients with multi organ involvement. ${ }^{14-16}$ Regarding prognosis SLE is incurable, but treatable. In the 1950s, most people diagnosed with SLE lived fewer than five years. Today over $90 \%$ survive for more than ten years, and many live relatively asymptomatically. $80-90 \%$ can expect to live a normal lifespan. ${ }^{17}$ We conduct this study to shade light on the clinical presentation of pediatric SLE. 


\section{Aim of study}

To define the pattern of disease Expression (clinical and investigation) in patients with childhood onset systemic lupus erythematosus.

\section{Patients and method}

\section{Settings}

S L E Clinic (out patient clinic of pediatric SLE) of Abu Alrich hospital-Cairo Egypt.

\section{Subject}

25 pediatric SLE patients who follow the clinic.

\section{Patients and method}

Prospective- retrospective observational descriptive case series report.

\section{Data collection}

Data collected by second author during her residency in Abu Alrich hospital to study rheumatology. The 25 patients randomly selected. She collects medical history information directly from the patients and their parents and reviews their files to collect the other information (e.g.: investigation results and clinical examination finding during course of the disease).

Some important definitions and information for patient selections:

a. All our patients were met the 1982 revised criteria for classification of SLE.

b. Onset of disease, defined as the initial manifestation clearly attributable to SLE, occurred before the age of 14 years.

c. Age at diagnosis, defined as the age when the patient fulfilled four or more of the 1982 revised criteria for the classification of SLE.

d. We include any manifestation developed during time of evolution of the disease, (defined as the time from the onset until the time of data collection).

\section{Results}

i. From 25 patients $17(68 \%)$ were females and $8(32 \%)$ males. Male to female ratio 1: 2.3 (Figure 1).

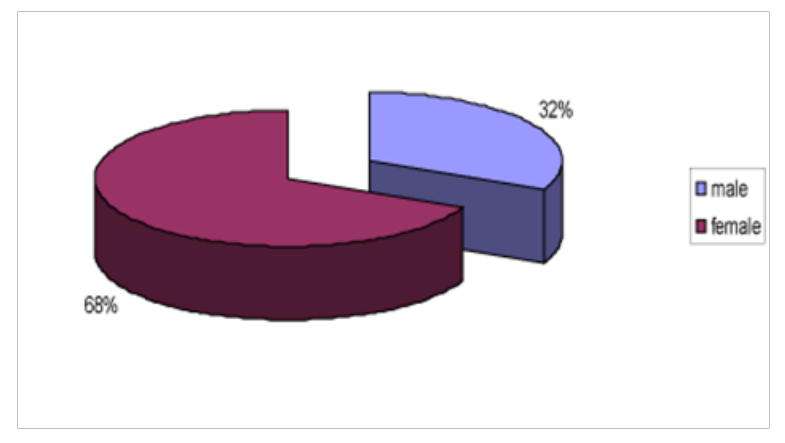

Figure I Male to female ratio.

ii. Age at diagnosis range from 4 to 15 years with mean of 9 years.

(Only one patient aged 4 years). iii. Duration of symptoms before diagnosis established range from one month to 7 years with mean of 8 months.

iv. Frequency of SLE classification criteria shown in Table 1.

v. Other clinical manifestation of SLE Shown in Table 2.

vi. The most frequent hematological abnormality Shown in Figure 2.

vii. Regarding other investigations shown in Table 3.

Table I Frequency of 1982 revised criteria for classification of SLE

\begin{tabular}{lll}
\hline Criterion & $\begin{array}{l}\text { Number } \\
\text { of Pts }\end{array}$ & $\%$ \\
\hline Malar rash & 3 & 12 \\
Discoid rash & 1 & 4 \\
photosensitivity & 12 & 48 \\
Oral ulcers & 12 & 48 \\
Arthritis & 9 & 36 \\
Serositis & 7 & 28 \\
Renal disorder & 21 & 84 \\
Neurological disorder & 0 & 0 \\
Hematological disorder & 11 & 44 \\
Immunological disorder & $9 / 15$ & 60 \\
Antinuclear antibody & $21 / 22$ & 95 \\
\hline
\end{tabular}

Table 2 other clinical manifestation of SLE

\begin{tabular}{lll}
\hline Clinical Presentation & $\begin{array}{l}\text { Number } \\
\text { of Pts }\end{array}$ & $\%$ \\
\hline Fever & 20 & 80 \\
Arthralgia & 12 & 48 \\
Dyspnea & 4 & 16 \\
Palpitation & 4 & 16 \\
Abdominal Pain & 9 & 36 \\
Anorexia & 12 & 48 \\
Hair Fall & 10 & 40 \\
Raynaud's Phenomena & 3 & 12 \\
Other Skin Manifestation & 6 & 24 \\
Lymphadenopathy & 3 & 12 \\
Headache & 5 & 20 \\
\hline
\end{tabular}

Table 3 Other laboratory abnormality of SLE

\begin{tabular}{llll}
\hline Investigation & $\begin{array}{l}\text { Number } \\
\text { of Pts }\end{array}$ & Abnormal & Percentage \\
\hline C3 & 17 & $14 \downarrow$ & 82 \\
C4 & 17 & $12 \downarrow$ & 70 \\
Anti double strand DNA & 15 & $9+\mathrm{ve}$ & 60 \\
RFT & 25 & 0 & 0 \\
LFT & 25 & 8 & 32 \\
\hline
\end{tabular}

RFT, Renal function test; LFT, liver function test 
viii. $7(28 \%)$ patients had urinary complain: oliguria 3, dark colored urine 5, dysuria 1 patient.

ix. $20(80 \%)$ had urinary changes. The most frequent urinary changes shown in Figure 3.

$\mathrm{x}$. Renal biopsy done in 13 patients with urinary involvement: finding shown in Figure 4.

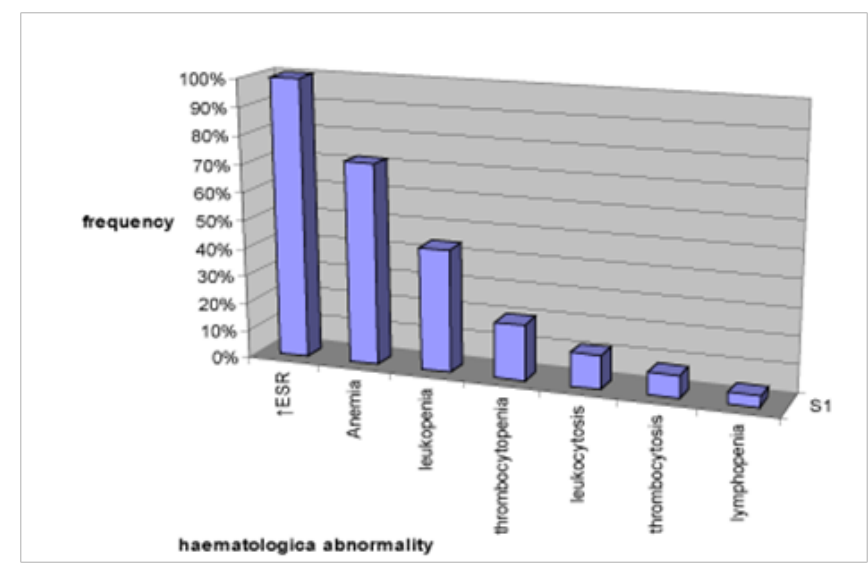

Figure 2 Hematological abnormality of SLE patients.

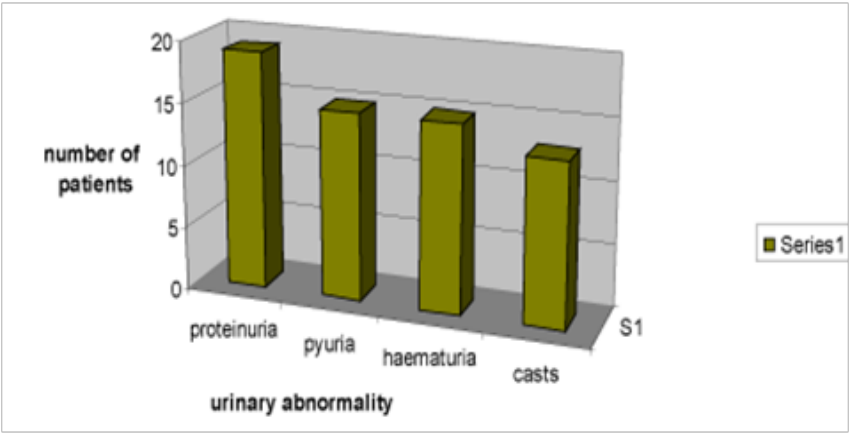

Figure 3 Urinary abnormality of SLE patients.

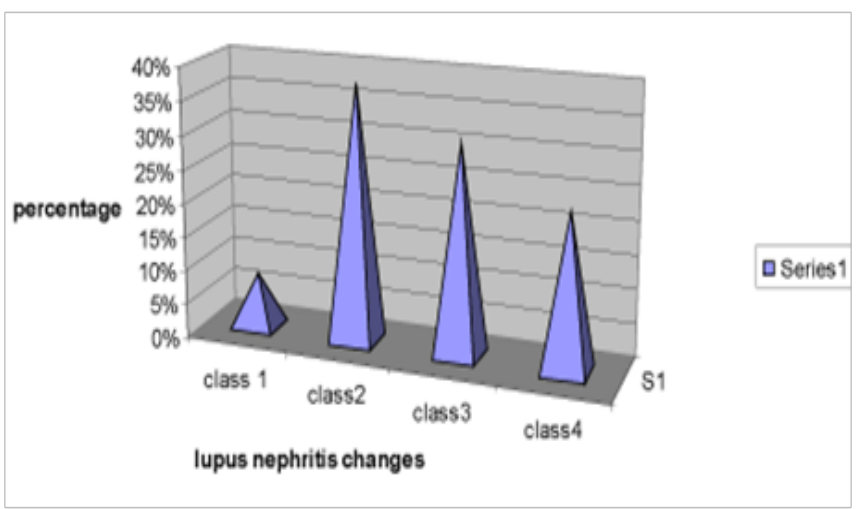

Figure 4 Renal biopsy changes of 15 patients with SLE nephritis.

\section{Discussion}

There have been several studies dealing with childhood onset SLE and their results suggested that age at onset modifies the expression of the disease in terms of clinical presentation, pattern of organ involvement and serological findings. ${ }^{18}$ We used 14 years as cut off age as the most often used cut off ages are 14 or 16 years at onset of disease. ${ }^{19-21}$ The onset of SLE is rare before the age of 5 years. ${ }^{22}$ Mean age 11 years (range 5-14). ${ }^{23}$ Regarding age our study show similar results. Female predominant male but our ratio less than others ${ }^{24}$ may be because we didn't take all of the patients but we choose random sample of them. Clinical presentation of our patients comparable to others ${ }^{25-27}$ but malar rash less and fever more. Our study show high percentage of renal involvement (84\%) but lupus nephritis is probably present to some degree in all children with SLE and is a major determinant of a long term outcome. ${ }^{28-30}$ In our study no patient with neuropsychatric disorder Except for headache which made the most common neuropsychiatric disorder in SLE patients. ${ }^{31}$ Although the existence of a specific lupus headache and the optimal approach to headache in SLE cases remains controversial. ${ }^{32}$ And that's why we didn't include headache in neuropsychiatric manifestation of SLE. Regarding investigations our results similar to others. ${ }^{19,33,34}$ However, the small number of patients that have been analyzed, the disparity in selection criteria for patient inclusion, or the definition of the variables, and our study didn't include all the SLE patients following the clinic make comparison of findings with previous reports difficult.

\section{Conclusion and recommendation}

The presentation and the clinical course of SLE have wide variability. Nephropathy, fever, and arthralgia and anorexia were the most common in pediatric patients as presenting clinical manifestations. There is marked delay between the starting of the disease manifestation and diagnosis, so alertness to the possibility of SLE as diagnosis in patients with variable manifestation should be there.

\section{Acknowledgment}

To Dr. Samia salah head of Rheumatology department of Abu Alrish hospital, Egypt.

\section{Reference}

1. James, William Berger, Imothy, et al. Andrews Diseases of the Skin Clinical Dermatology. (10 ${ }^{\text {th }}$ edn), Saunders, Philadelphia, USA, 2005;p. $1-51$.

2. Nepom BS, Schaller JG. Childhood systemic lupus erythematosus. Prog Clin Rheumatol. 1984;1:33-69.

3. Tucker LB, Menon S, Isenberg DA. Systemic lupus in children: daughter of the Hydra? Lupus. 1995;4(2):83-85.

4. Schaller J. Lupus in childhood. Clin Rheum Dis. 1982;8(1):219-228.

5. Ting CK, Hsieh KH. A long term immunological study of childhood onset systemic lupus erythematosus. Ann Rheum Dis. 1992;51(1):45-51.

6. Rosenberg AM. Systemic lupus erythematosus in children. Springer Semin Immunopathol. 1994;16(2-3):261-279.

7. Anisur Rahman, David A Isenberg. Systemic Lupus Erythematosus. $N$ Engl J Med. 2008;358(9):929-939.

8. Lupus Foundation of America. (2007).

9. Anthony Fauci, Eugene Braunwald, Dennis Kasper, et al. Harrison's Principles of Internal Medicine. (1 $7^{\text {th }}$ edn), McGraw-Hill Companies, New York, USA, 2008.

10. Lupus: Symptoms -MayoClinic.com. (2008). 
11. Article on the classification of rheumatic diseases. Rheumatology.org (2011).

12. Revision of Rheumatology.org's diagnostic criteria. Rheumatology.org (2011).

13. Edworthy SM, Zatarain E, McShane DJ, et al. Analysis of the 1982 ARA lupus criteria data set by recursive partitioning methodology: new insights into the relative merit of individual criteria. $J$ Rheumatol. 1988;15(10):1493-1498.

14. Vasudevan AR, Ginzler EM. Established and novel treatments for lupus. The Journal of Musculoskeletal Medicine. 2009;26(8).

15. FDA approves first new lupus drug in 56 years. (2011).

16. Handout on Health: Systemic Lupus Erythematosus, National Institute of Arthritis and Musculoskeletal and Skin Diseases, National Institutes of Health, U.S. Department of Health and Human Services. (2010).

17. Prognosis and a Hopeful Future". Lupus Foundation of America website. Retrieved 14 December 2010

18. Meislin AG, Rothfield N. Systemic lupus erythematosus in childhood Pediatrics. 1989;83(2):235-239.

19. Costallat LTL, Coimbra AMV. Systemic lupus erythematosus: clinical and laboratory aspects to age at disease onset. Clin Exp Rheumatol. 1994;12(6):603-607.

20. Huong DLT, Weschler B, Piette JC, et al. Clinical manifestations and outcome of childhood systemic lupus erythematosus: a retrospective study of 50 cases. Eur J Int Med. 1993;4:15-22.

21. Hashimoto H, Tsuda H, Hirano $T$, et al. Differences in clinical and immunological findings of systemic lupus erythematosus related to age of 50 cases. J Rheumatol. 1993;14(3):497-501.

22. Dubois EL, Tuffanelli DL. Clinical manifestations of systemic lupus erythematosus. Computer analysis of 520 cases. JAMA. 1964;190:104113.
23. Lehman TJ, McCurdy DK, Bernstein BH, et al. Systemic lupus erythematosus in the first decade of life. Pediatrics. 1989;83(2):235-239.

24. Celermeyer DS, Thorner PS, Baumal R, et al. Sex differences in childhood lupus nephritis. Am J Dis Child. 1984;138(6):586-588.

25. Balkaran BN, Roberts LA, Ramcharan J. Systemic lupus erythematosus in Trinidadian children. Ann Trop Paediatr. 2004;24(3):241-244.

26. Alsaeid K, Kamal H, Haider MZ, et al. Systemic lupus erythematosus in Kuwaiti children; organ system involvement and serological findings. Lupus. 2004;13(8):613-617.

27. Sibbitt WL Jr, Brandt JR, Johnson CR, et al. The incidence and prevalence of neuropsychiatric syndromes in pediatric onset systemic lupus erythematosus. J Rheumatol. 2002;29(7):1536-1542.

28. Cameron JS. Lupus nephritis in childhood and adolescence. Pediatr Nephrol. 1994;8(2):23-249.

29. Cassidy JT, Sullivan DB, Petty RE, et al. Lupus nephritis and encephalopathy: Prognosis in 58 children. Arthritis Rheum. 1977;20(2):315-322.

30. Barron KS, Silverman DE, Gonzales J, et al. Clinical, serologic and immunogenetic studies in childhood-onset systemic lupus erythematosus. Arthritis Rheum. 1993;36(3):340-348.

31. Honczarenko K, Budzianowska A, Ostanek L. Neurological syndromes in systemic lupus erythematosus and their association with antiphospholipid syndrome. Neurol Neurochir Pol. 2008;42(6):513-517.

32. Omdal R. Some controversies of neuropsychiatric systemic lupus erythematosus. Scand J Rheumatol. 2002;31(4):192-197.

33. Ward MM, Dawson DV, Kredich DW, et al. Expression of IgM and IgG auto antibodies in pediatric and adult systemic lupus erythematosus. Clin Immunol Immunopathol. 1990;55(2):273-284.

34. Platt JL, Burke BA, Fish AJ, et al. systemic lupus erythematosus in the first two decades of life. Am J kidney Dis. 1982;2(1 Suppl 1):212-222. 